\title{
Electrochemistry of Xanthine Oxidase and Its Interaction with Nitric Oxide
}

\author{
Hui ZHOU,* Yi Xu,* Ting ChEN,* Iwao SuZUKI, ** and Genxi LI*广 \\ *Department of Biochemistry and National Key Laboratory of Pharmaceutical Biotechnology, \\ Nanjing University, Nanjing 210093, P. R. China \\ **Graduate School of Pharmaceutical Sciences, Tohoku University, Aramaki, Aoba, Sendai 980-8578, Japan
}

\begin{abstract}
With the help of nanocrystalline $\mathrm{TiO}_{2}$, the direct electrochemistry of xanthine oxidase (XOD) was achieved and two pairs of redox waves were observed. The interaction between XOD and nitric oxide (NO) was also investigated. The experimental results reveal that $\mathrm{NO}$ can be reduced at a $\mathrm{XOD}$-nano $\mathrm{TiO}_{2}$ film modified electrode. When the $\mathrm{NO}$ concentration was low, the reduced product, $\mathrm{HNO}$, would inactivate the protein. However, when the NO concentration was high, $\mathrm{HNO}$ would continue to react with $\mathrm{NO}$ to form $\mathrm{N}_{2} \mathrm{O}_{2}{ }^{-}$and $\mathrm{N}_{3} \mathrm{O}_{3}^{-}$, which would not inhibit XOD, and thus the amount of active protein did not decrease any further.
\end{abstract}

(Received June 27, 2005; Accepted November 1, 2005)

\section{Introduction}

In mammalian cells, xanthine oxidase (XOD) is a metalloflavoprotein that plays a variety of important roles in the metabolism of purine and pyrimidine. It can catalyze the oxidation of hypoxanthine to xanthine and xanthine to uric acid, respectively, with a concomitant reduction of the oxygen molecule. ${ }^{1,2}$ Although XOD has been isolated from a wide range of organisms, all of these proteins have similar molecular weights and compositions of the redox active sites. ${ }^{1,3}$ Each subunit of XOD contains a molybdenum center, two nonidentical [2Fe-2S] clusters, and a flavin adenine dinucleotide (FAD) cofactor. ${ }^{4,5}$ Recently, increasing attention has been devoted to investigating XOD by the electrochemical technique. ${ }^{6,7}$

Nitric oxide (NO) is an important regulatory molecule that plays essential roles in many physiological and biological processes, including neurotransmission, platelet aggregation, macrophage function, and vasodilation. ${ }^{8}$ NO can regulate and protect some physiological processes when its concentration is low. On the other hand, when the concentration is high, NO deactivates most enzymes and displays toxicity..$^{9,10}$ Studies have revealed that $\mathrm{NO}$ at a high concentration reacts with $\mathrm{XOD}$, glucose oxidase and horseradish peroxidase, and inhibits their catalytic activity. ${ }^{9-12}$ In vivo $\mathrm{NO}$ can be synthesized by nitric oxide synthases (NOSs), which metabolizes arginine to citrulline. ${ }^{13,14}$ It can also be synthesized by XOD under hypoxic conditions, which catalyzes the reduction of nitrite to NO. ${ }^{15}$ Therefore, studies on the interaction between XOD and NO have received increasing interest. ${ }^{16,17}$

The electrochemical technique has been a feasible way to study the interaction between biological molecules. ${ }^{18-22}$ However, since the electrochemistry of XOD is very difficult to achieve, only a few electrochemical studies on XOD have been reported, not to mention electrochemical studies on the interaction between XOD and NO.

† To whom correspondence should be addressed.
Recently, an increasing number of nano materials have been employed in bioelectrochemical studies. Nanocrystalline $\mathrm{TiO}_{2}$ is a kind of nanomaterial that possesses good biocompatibility and chemical stability. It has been reported to be a suitable material for the immobilization of heme proteins at an electrode surface, and to enhance their electron-transfer reactivity. ${ }^{23}$ In this paper, we report on direct electron transfer of XOD with the help of nanocrystalline $\mathrm{TiO}_{2}$, and the interaction between XOD and NO.

\section{Materials and Methods}

\section{Materials}

Cow milk XOD was purchased from Sigma and used directly without further purification. Stock solutions $(1 \mathrm{Unit} / \mathrm{mL})$ were kept at a temperature of $4^{\circ} \mathrm{C}$. Nanocrystalline $\mathrm{TiO}_{2}$ powder was obtained from Nanjing Haitai Nano Company with particle size at about $35 \mathrm{~nm}$. Water was purified with a Milli-Q purification system to a specific resistance $>16 \mathrm{M} \Omega \mathrm{cm}^{-1}$, and was used to prepare all solutions. $0.1 \mathrm{M}$ phosphate buffer solutions (PBS) of various $\mathrm{pH}$ levels were prepared by mixing two stock solutions of $0.1 \mathrm{M} \mathrm{Na}_{2} \mathrm{HPO}_{4}$ and $0.1 \mathrm{M} \mathrm{NaH}_{2} \mathrm{PO}_{4}$. All other reagents were of analytical grade.

\section{Sample preparation}

NO stock solutions were prepared according to the following procedure. NO gas was generated based on the stoichiometric reaction:

$$
\mathrm{NaNO}_{2}+\mathrm{H}_{2} \mathrm{SO}_{4} \longrightarrow \mathrm{NO} \uparrow+\mathrm{H}_{2} \mathrm{O}+\mathrm{Na}_{2} \mathrm{SO}_{4} .
$$

The whole process was performed under a nitrogen atmosphere to prevent $\mathrm{NO}$ conversion to $\mathrm{NO}_{\mathrm{x}}$ in the presence of $\mathrm{O}_{2}$. $\mathrm{NO}$ gas was purified by passing through three separate trap units: two $\mathrm{NaOH}$ solutions $(3 \mathrm{~mol} / \mathrm{L})$ first, and then pure water. Finally, the $\mathrm{NO}$ gas was saturated in a $0.1 \mathrm{~mol} / \mathrm{L}$ phosphate buffer $(\mathrm{pH}$ 7.4). The concentration of $\mathrm{NO}$ in the saturated buffer is estimated to be $1.8 \mathrm{mmol} / \mathrm{L}$ at $25^{\circ} \mathrm{C}^{24} \mathrm{NO}$ analyte solutions 


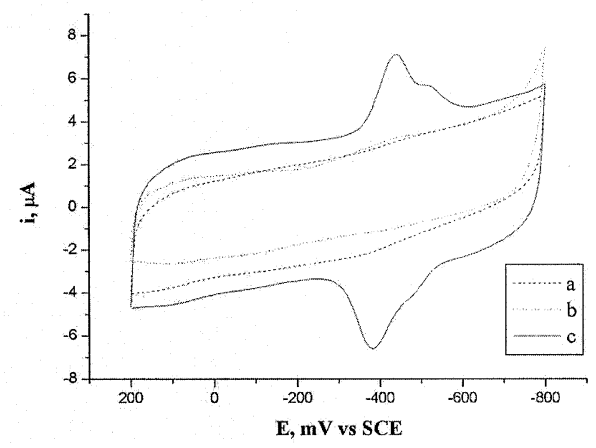

Fig. 1 Cyclic voltammograms in $0.1 \mathrm{M}$ PBS with $\mathrm{pH} 6.0$ obtained at (a) bare PG electrode (b) nanocrystalline $\mathrm{TiO}_{2}$ alone modified

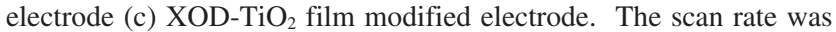
$100 \mathrm{mV} / \mathrm{s}$.

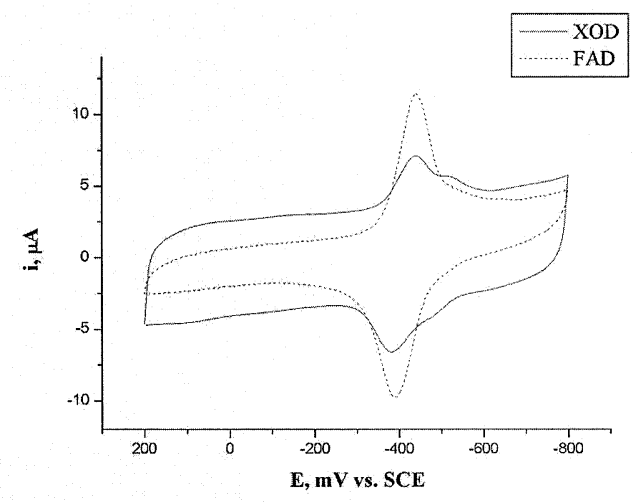

Fig. 2 Cyclic voltammograms in $0.1 \mathrm{M}$ PBS with $\mathrm{pH} 6.0$ obtained at a XOD- $\mathrm{TiO}_{2}$ film modified electrode (solid) and a $\mathrm{FAD}-\mathrm{TiO}_{2}$ film modified electrode (dot). The scan rate was $100 \mathrm{mV} / \mathrm{s}$.

with desired concentrations were freshly diluted from this stock solution. Other reagents were of analytical grade.

\section{Electrode preparation}

The substrate pyrolytic graphite (PG) electrode was first polished using rough and fine sand papers. It was then polished to mirror smoothness with alumina (particle size of about 0.05 $\mu \mathrm{m})$ and water. Finally, the electrode was thoroughly washed with water, and then treated in an ultrasonic bath for about 5 min, with pure water and ethanol, respectively. The electrode was thus able to be ready for use. Prior to the experiments, a test solution was bubbled thoroughly with high-purity nitrogen. Then, a stream of nitrogen was blown gently across the surface of the solution in order to maintain the solution anaerobic condition throughout the experiments.

An $\mathrm{XOD} / \mathrm{TiO}_{2}$ film was prepared as follows. An aqueous mixture of $10 \mu \mathrm{L}$ XOD $(1 \mathrm{Unit} / \mathrm{mL})$ and $\mathrm{TiO}_{2}(1 \mathrm{mg} / \mathrm{mL})$ with a ratio of 1:1 was dropped onto the surface of a PG electrode. After that, an eppendorf tube was fitted over the electrode for 2 $h$ to ensure that the water evaporated slowly and a more uniform film structure could be formed. The film was then dried overnight at room temperature. Finally, the electrode was thoroughly rinsed with pure water. The modified electrode was kept in a phosphate buffer solution of $\mathrm{pH} 7.2$ at $4^{\circ} \mathrm{C}$ when not in use.

\section{Electrochemical measurements}

Electrochemical experiments were performed with a PARC

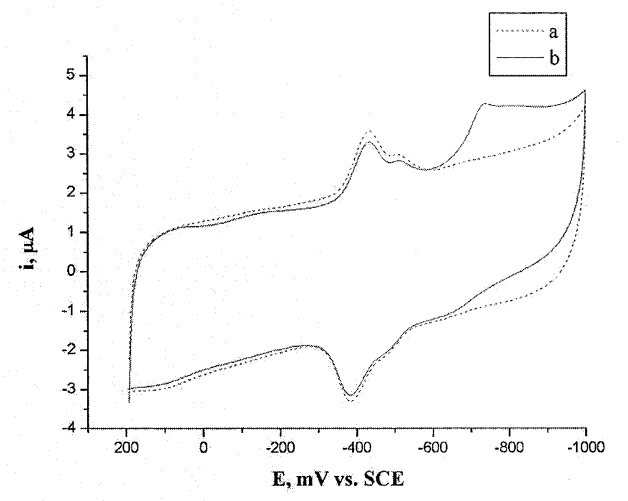

Fig. 3 Cyclic voltammograms of a $\mathrm{XOD}-\mathrm{TiO}_{2}$ film modified electrode in PBS with pH 6.0 containing (a) no $\mathrm{NO}$ and (b) $1 \times 10^{-4}$ $\mathrm{mol} / \mathrm{L} \mathrm{NO}$. The scan rate was $50 \mathrm{mV} / \mathrm{s}$.

283 potentiostat/galvanostat (EG\&G, Princeton, NJ), using a three-electrode configuration. A saturated calomel electrode (SCE) and a platinum electrode served as reference and counter electrodes, respectively. Potentials are reported with respect to SCE unless specially stated. A $50 \mathrm{~mL}$ reagent bottle was used for the electrolytic cell. A multi-block heater (LAB-LINE Instruments, Inc., USA) was employed to maintain the experimental temperature at $20 \pm 0.5^{\circ} \mathrm{C}$. The electrochemical results reported here are all reproduced for 5 times. The current of each peak was measured as the distance from the vertex of the peak to the tangent of its baseline. To study the interaction between XOD and NO, the electrode was first kept at a potential of $200 \mathrm{mV}$ for $5 \mathrm{~min}$. The electrode was scanned for 20 cycles in the range from 200 to $-1000 \mathrm{mV}$, so as to keep the height of the original two pair of peaks constant, before NO was added to the buffer.

\section{Results and Discussion}

It is usually very difficult to obtain the electrochemical response of XOD. However, with the help of nanocrystalline $\mathrm{TiO}_{2}$, the direct electrochemistry of XOD can be achieved. Figure 1 shows cyclic voltammograms (CVs) obtained at a PG electrode modified with $\mathrm{XOD}^{-\mathrm{TiO}_{2}}$ film in a $0.1 \mathrm{M}$ pH 6.0 phosphate buffer solution. It should be noticed that two pairs of peaks can be observed (Peaks I and II). One pair is located at $-0.440 \mathrm{~V}$ and $-0.382 \mathrm{~V}$ (Peak I), while the other is at $-0.513 \mathrm{~V}$ and $-0.479 \mathrm{~V}$ (Peak II). However, it is clear that no voltammetric response was observed either at a bare PG electrode or a nanocrystalline $\mathrm{TiO}_{2}$-alone modified electrode. Such results indicate that these two pairs of peaks are due to the reduction and oxidation of XOD at the electrode. The $\mathrm{XOD}-\mathrm{TiO}_{2}$ film modified PG electrode was fairly stable. No obvious decrease in peak currents was observed after 1 week.

The characteristics of Peak I was examined for the first time. In the potential scan range from 20 to $250 \mathrm{mV} / \mathrm{s}$, both the cathodic and anodic peaks currents were proportional to the scan rate $(v)$, which indicates a characteristic of thin-layer electrochemical behavior. ${ }^{25}$ At a scan rate range of 50 to 200 $\mathrm{mV} / \mathrm{s}$, it could be found that the width at the half height of the first pair of peaks, $W_{1 / 2}$, remained constant for both the cathodic and anodic peaks, and the ratio of cathodic current to anodic one was close to one, which suggests that XOD undergoes a quasireversible redox process when co-modified with $\mathrm{TiO}_{2}$ on the PG electrode. The cathodic peak potential $\left(E_{\mathrm{pIc}}\right)$ was measured to 

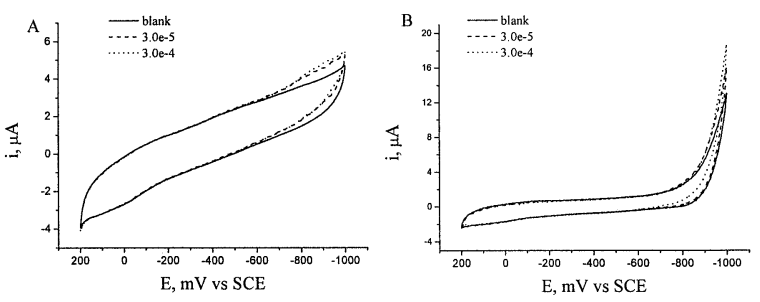

Fig. 4 Cyclic voltmmograms in $0.1 \mathrm{M}$ PBS with $\mathrm{pH} 6.0$ obtained at A) bare electrode and $\mathrm{B}$ ) $\mathrm{TiO}_{2}$ only modified electrode in the absence (solid line) and presence of $\mathrm{NO}$ at concentrations of $30 \mu \mathrm{M}$ (dash line) and $300 \mu \mathrm{M}$ (dot line). The scan rate was $50 \mathrm{mV} / \mathrm{s}$.

be $c a$. $-0.440 \mathrm{mV}$, which is consistent with values reported for free FAD and the enzyme-bound FAD. ${ }^{26}$ An FAD $^{-T_{i O}}$ modified electrode was also used to distinguish these two pairs of peaks, as shown in Fig. 2. Therefore, the peaks, located at $-0.440 \mathrm{~V}$ and $-0.382 \mathrm{~V}$, contributed to the FAD redox reaction.

As for the second pair of peaks (Peak II) with a formal standard potential $\left(E_{\mathrm{pII}}^{0^{\prime}}\right)$ of $-0.502 \mathrm{mV}$, the peak separation $\left(\Delta E_{\mathrm{pII}}\right)$ is estimated to be $51.0 \mathrm{mV}$, which means that the electron transfer number of Peak II is one (theoretical values of $58 / n$ for a Nersntian process). ${ }^{27}$ Also, the value of $E_{\text {pII }}^{\prime \prime}$ is close to that of the $[2 \mathrm{Fe}-2 \mathrm{~S}]$ II cluster and is much different from that of the $[2 \mathrm{Fe}-2 \mathrm{~S}] \mathrm{I}_{\text {cluster. }}{ }^{28}$

It is still unknown how the nanocrystalline $\mathrm{TiO}_{2}$ caused the enzyme to exhibit this electrochemical behavior, and further work should be performed. However, the electrochemical response of XOD has obviously been observed, and the interactions between XOD and NO might possibly be studied by the electrochemical method. As is shown in Fig. 3, in the presence of $1 \times 10^{-4} \mathrm{M} \mathrm{NO}$, a new peak appears at a potential of $-732 \mathrm{mV}$, in the negative direction of the redox pairs of XOD. Notably, no corresponding signal is visible at a bare PG electrode or an electrode modified with nanocrystalline $\mathrm{TiO}_{2}$ alone under the same condition (Fig. 4).

Cyclic voltammetric measurements were also performed when adding a series of $\mathrm{NO}$ concentrations at a scan range from 200 to $-1000 \mathrm{mV}$, as displayed in Figs. 5 and 6. Figure 5 shows that the peaks currents of the FAD cofactor and the [2Fe-2S] II cluster gradually decrease with an increase of the NO concentration from $1 \times 10^{-5} \mathrm{M}$ to $1 \times 10^{-4} \mathrm{M}$. On the other hand, parallel experiments performed for investigating the effect of NO on the FAD cofactor alone show that the peak shape of FAD does not change after adding NO into the test solution. Thus, the concentration of $\mathrm{NO}$ is negatively correlative to the peak currents of both FAD and the [2Fe-2S] II cluster, and the molecule numbers of activated protein will decrease with increasing NO concentration, which confirms the previous report that $\mathrm{NO}$ can deactivate the enzyme and display toxicity. ${ }^{9,10}$ We suggest that the deactivation effect is due to the reduction product of $\mathrm{NO}$ by $\mathrm{XOD}, \mathrm{HNO}$, at the electrode surface, ${ }^{17}$ and that NO binding and reduction might occur at the molybdenum site. The proposed mechanism for the reduction of NO by XOD can be expressed by the following equations:

$$
\begin{aligned}
& \mathrm{XOD}[\mathrm{Mo}(\mathrm{IV})]+\mathrm{NO} \longrightarrow \mathrm{XOD}[\mathrm{Mo}(\mathrm{IV})]-\mathrm{NO}, \\
& \mathrm{XOD}[\mathrm{Mo}(\mathrm{IV})]-\mathrm{NO}+\mathrm{e}+\mathrm{H}^{+} \longrightarrow \mathrm{XOD}[\mathrm{Mo}(\mathrm{IV})]+\mathrm{HNO}
\end{aligned}
$$

(at electrode).

More interestingly, as shown in Fig. 6, when the NO concentration increases from $1.2 \times 10^{-4} \mathrm{M}$ to $3.4 \times 10^{-4} \mathrm{M}$, the

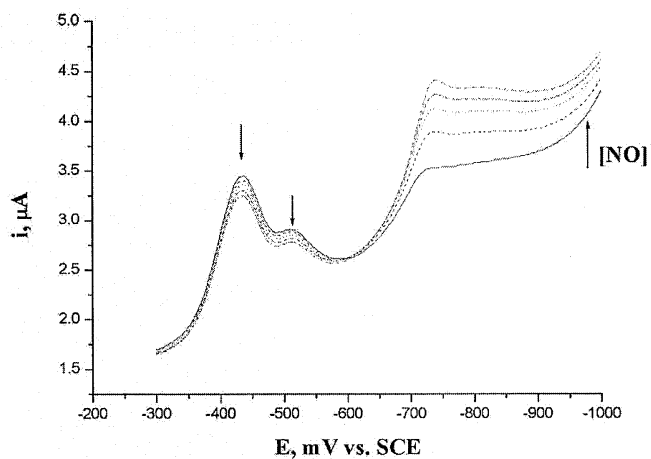

Fig. 5 Part of voltammograms of $\mathrm{XOD}-\mathrm{TiO}_{2}$ film modified electrode in PBS with $\mathrm{pH} 6.0$ containing $\mathrm{NO}$ with concentration of $20,40,60,80$ and $100 \mu \mathrm{M}$. The scan rate was $50 \mathrm{mV} / \mathrm{s}$. The actual scan range was from 200 to $-1000 \mathrm{mV}$.

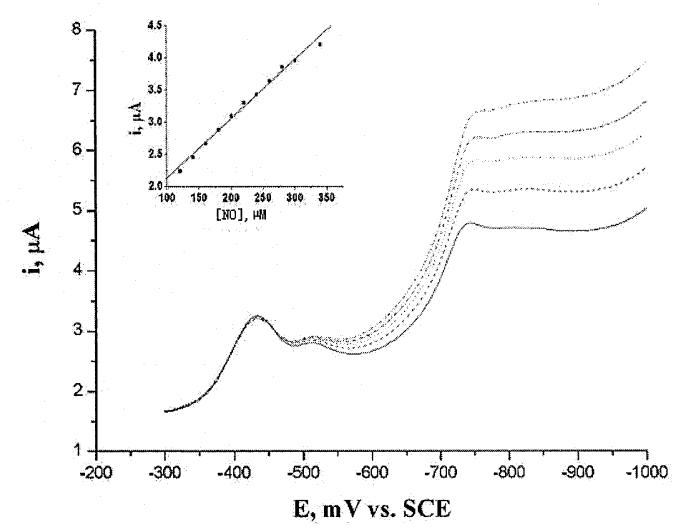

Fig. 6 Part of voltammograms of a XOD-TiO ${ }_{2}$ film modified electrode in PBS with pH 6.0 containing $\mathrm{NO}$ with concentrations of $120,160,200,240$ and $280 \mu \mathrm{M}$. The scan rate was $50 \mathrm{mV} / \mathrm{s}$. The actual scan range was from 200 to $-1000 \mathrm{mV}$. The inset shows the linear calibration curve between the catalytic peak current and the NO concentration.

cathodic peak current of FAD does not change. On the other hand, because the based lines of the cathodic curves of the [2Fe-2S] II cluster in the voltammograms rise with an increase of the catalytic peak current of $\mathrm{NO}$, the actual peak current of the $[2 \mathrm{Fe}-2 \mathrm{~S}]$ II cluster also does not change. Further, a linear relationship between the peak current of $\mathrm{NO}$ and its concentration is obtained. Meanwhile, all of these results indicate that in this $\mathrm{NO}$ concentration range, the amount of active protein remains constant. A possible explanation might be that although protonated $\mathrm{HNO}$ is the majority in the $\mathrm{pH} 6.0$ test solution, $\mathrm{NO}^{-}$still exists in the solution. As a result, $\mathrm{NO}^{-}$ might react with $\mathrm{NO}$ according to the following reactions if there are more $\mathrm{NO}$ molecules:

$$
\begin{aligned}
& \mathrm{NO}^{-}+\mathrm{NO} \longrightarrow \mathrm{N}_{2} \mathrm{O}_{2}^{-}, \\
& \mathrm{N}_{2} \mathrm{O}_{2}^{-}+\mathrm{NO} \longrightarrow \mathrm{N}_{3} \mathrm{O}_{3}^{-} .
\end{aligned}
$$

Both $\mathrm{N}_{2} \mathrm{O}_{2}{ }^{-}$and $\mathrm{N}_{3} \mathrm{O}_{3}{ }^{-}$will not decrease the activity of XOD. ${ }^{29}$ Therefore, when the NO concentration is very high, HNO, the reduction product of $\mathrm{NO}$, would continue reacting with NO. Consequently, the enzyme is not inactivated. 


\section{Conclusion}

With the help of nanocrystalline $\mathrm{TiO}_{2}$, two pairs of peaks of XOD have been obtained corresponding to the FAD cofactor and the $[2 \mathrm{Fe}-2 \mathrm{~S}]$ II center. Furthermore, the interaction between XOD and NO was studied via the electrochemical technique. When the NO concentration was lower than 120 $\mu \mathrm{mol}$, an inhibition effect of NO on these two active centers could be detected, based on a decrease of the peak currents. Interestingly, as the concentration of NO increased above this value, NO was progressively reduced without any further enzyme inactivation, which might have been due to the unharmful products at a higher NO concentration.

\section{Acknowledgements}

This work is supported by the National Natural Science Foundation of China (Grant No. 90406005) and the Program for New Century Excellent Talents in University, the Chinese Ministry of Education.

\section{References}

1. R. Hille and T. Nishino, FASEB J., 1995, 9, 9995.

2. R. Harrison, Free Radical. Biol. Med., 2002, 33, 774.

3. R. Hille, Chem. Rev., 1996, 96, 2757.

4. V. Massey, P. E. Brumby, and H. Komai, J. Biol. Chem., 1969, 244, 1682.

5. C. Enroth, B. T. Eger, K. Okamoto, T. Nishino, T. Nishino, and E. F. Pai, PNAS, 2000, 97, 10723.

6. L. Wang and Z. Yuan, Anal. Sci., 2004, 20, 635.

7. M. M. Corresia dos Santos, P. M. P. Sousa, M. Lurdes, S. Goncalves, M. J. Romao, I. Moura, and J. J. G. Moura, Eur. J. Biochem., 2004, 271, 1329.

8. R. F. Eich, T. Li, D. D. Lemon, D. H. Doherty, S. R. Curry, J. F. Aitken, A. J. Mathews, K. A. Johnson, R. D. Smith, G. N. Phillips, Jr., and J. S. Olson, Biochemistry, 1996, 35, 6976.
9. R. Farias-Eisner, G. Chaudhuri, E. Aeberhard, and J. Fukuto, J. Biol. Chem., 1996, 271, 6144.

10. S. Gupta, N. Ahmad, and H. Mukhtar, Cancer Res., 1998, 58,1785 .

11. K. Ichimori, M. Fukahori, H. Nakazawa, K. Okamoto, and T. Nishino, J. Biol. Chem., 1999, 274, 7763.

12. C. Lee, X. Liu, and J. L. Zweier, J. Biol. Chem., 2000, 275 , 9369.

13. D. S. Bredt, P. M. Hwang, C. E. Glatt, C. Lowenstein, R. R. Reed, and S. H. Snyder, Nature, 1991, 351, 714.

14. D. S. Bredt and S. H. Snyder, Neuron, 1992, 8, 3.

15. H. Li, A. Samouilov, X. Liu, and J. L. Zweier, Biochemstry, 2003, 42, 1150.

16. M. Saleem, I. Gilibert, and H. Ohshima, Free Radical. Biol. Med., 2002, 33 (123 Suppl. 1), S49.

17. M. Saleem and H. Ohshima, Biochem. Biophys. Res. Commun., 2004, 315, 455.

18. C. Fan, X. Chen, G. Li, J. Zhu, D. Zhu, and H. Scheer, Phys. Chem. Chem. Phys. (J. Chem. Soc., Faraday Trans.), 2000, 2, 4409.

19. W. Peng, X. Liu, W. Zhang, and G. Li, Biophys. Chem., 2003, 106, 267.

20. W. Zhang, C. Fan, Y. Sun, and G. Li, Biochim. Biophys. Acta-General Subjects, 2003, 1623, 29.

21. Z. Sun, J. Hu, Y. Lu, and Q. Li, Analyst, 2003, 128, 930.

22. B. Ge, F. W. Scheller, and F. Lisdat, Biosens. Bioelectron., 2003, 18, 295.

23. Q. Li, G. Luo, and J. Feng, Electroanalysis, 2001, 13, 359.

24. F. Bedioui, S. Trevin, and J. Devynck, J. Electroanal. Chem., 1994, 377, 295.

25. R. W. Murray, in "Electroanalytical Chemistry", ed. A. J. Bard, 1984, Marcel Dekker, New York, 191.

26. C. G. Rodrigues and A. G. Wedd, J. Electroanal. Chem., 1991, 312, 131.

27. A. J. Bard and L. R. Faulkner, "Electrochemical Methods, Fundamentals and Applications", 2001, John Wiley and Sons, New York.

28. J. Hunt, V. Massey, W. R. Dunham, and R. H. Sands, J. Biol. Chem., 1993, 268, 18686.

29. N. M. Cook, M. Shinyashiki, M. I. Jackson, F. A. Leal, and J. M. Fukuto, Arch. Biochem. Biophys., 2003, 410, 89. 